\title{
COMBINED EFFECTS OF EXERCISE AND RESTRICTION OF ENERGY INTAKE ON MODERATELY OBESE WOMEN
}

\author{
D. P. THOMAS, PhD**, A. Z. BELKO, PhD*, G. L. MULROY, MSc**, J. D. HAAS, PhD* and D. A. ROE, MD* \\ *Division of Nutritional Sciences, Cornell University \\ **Department of Physical Education, Ithaca College, Ithaca, New York 14850, USA
}

\begin{abstract}
The current study was designed to assess the contribution of dietary-induced weight reduction on improvements in functional capacity in moderate obesity. Twelve females $(\bar{X}$ age $=29 \mathrm{yr}, \bar{X}$ fat percentage $=37 \%$ ) served as subjects for the study.

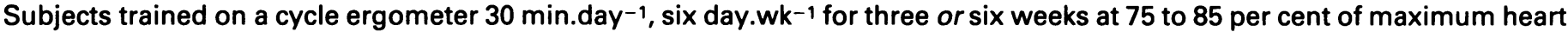
rate (HR max). Improvements in maximal oxygen uptake $\left(\Delta \mathrm{VO}_{2} \max \left(\cdot \mathrm{min}^{-1}\right)\right.$ and functional capacity $\left(\Delta \mathrm{VO}_{2}\right.$ max $\left.\mathrm{ml} . \mathrm{kg}^{-1} \mathrm{~min}^{-1}\right)$ were compared in an attempt to separate out training and dietary effects respectively. Measurements were also taken on both the cycle ergometer and treadmill to test for any specificity of training effects. Changes in body composition were assessed by densitometry. Following three weeks of training, there was an average increase in $\mathrm{VO}_{2} \mathrm{max} \mathrm{ml.kg}^{-1} \mathrm{~min}^{-1}$ on the cycle ergometer and the treadmill of 14 and 19 per cent respectively. By six weeks, this had increased to 18 and 26 per cent respectively. The contribution of weight reduction to the improvements in functional capacity was calculated to range from 20 to 33 per cent. Thus, both energy restriction and exercise training appear to be effective means of improving functional capacity in moderately obese women.
\end{abstract}

Key words: Training, Energy restriction, Obesity, Females.

\section{INTRODUCTION}

Obesity in both males and females is known to be associated with a marked reduction in physical working capacity. Thus, in individuals with greater than 30 per cent body fat, there is an inverse relationship between physical capacity and body weight. These individuals demonstrate lower aerobic capacities $\left(\mathrm{VO}_{2} \max \right)$ than age-matched populations norms (Curtis and Bradfield, 1971). Increasing energy expenditure by physical training (Franklin et al, 1979; Lewis et al, 1976), or reducing caloric intake (Zuti and Goldring, 1976) have both been shown to produce similar reductions in total body weight in obese females. Their effects on body composition and selected physiological and biochemical parameters, however, may be markedly different. Thus weight reduction in obesity brought about by physical training has been associated with numerous metabolic adaptations. These include preservation of lean body mass (LBM), improved muscle endurance, increased insulin sensitivity, improved high-density lipoprotein cholesterol/low-density lipoprotein cholesterol ratio, and improved ability of the muscle cell to take up glucose and metabolise fats (Lewis et al, 1976; Mandroukas et al, 1984; Zuti and Golding, 1976). It is for this reason that physical training is recommended for the treatment of obesity. However, unless it is combined with food restriction, physical training may or may not result in a decrease in body weight, due to a presumed elevation in energy intake in proportion to the exercise-induced increase in energy expenditure (Mandroukas et al, 1984; Woo et al, 1982a; Woo et al, 1982b).

Very few studies have looked at the combined effects of exercise and reduction in energy intake in obese women (Belko et al, 1985; Warwick and Garrow, 1981; Zuti and

Address for correspondence:

Dr. D. P.Thomas, PhD

Biodynamics Laboratory

University of Wisconsin

2000 Observatory Drive

Madison,

WI 53706, USA
Golding, 1976). We have recently reported the effects of exercise and energy restriction on riboflavin requirements in overweight women. In addition to the riboflavin status parameters, we also measured the changes in aerobic capacity as maximal oxygen uptake ( $\mathrm{VO}_{2} \max \left(\cdot \mathrm{min}^{-1}\right)$ and functional capacity $\left(\mathrm{VO}_{2}\right.$ max ml. $\left.\mathrm{kg}^{-1} \mathrm{~min}^{-1}\right)$ in an attempt to separate out the effects produced by exercise training alone, and in combination with a reduced caloric intake. As the mode of training was cycling on a bicycle ergometer, a second purpose was to investigate any specificity of training effects by comparing oxygen uptake values obtained on the treadmill with those obtained during cycling.

\section{METHODS}

\section{Selection of Subjects}

Twelve moderately overweight women aged $20-38$ years, were selected from over 50 volunteers. Moderately overweight was defined as a weight for height greater than $115 \%$ but less than $130 \%$ of the ideal body weight developed in 1959 by the Metropolitan Life Insurance Company. Pre-study screening included health assessment by medical history, physical examination, electrocardiogram, and haematological and biochemical measures. Suitability of subjects for the exercise programme was assessed by the electrocardiogram and a submaximal exercise walking treadmill test.

Participation was by informed consent. Reasons for exclusion of volunteers included: (1) intake of drugs including oral contraceptives; (2) physical signs of health impairment; (3) history of fad or crash dieting; (4) weight for height ratio outside of the specified $115-130 \%$ range; and (5) history of knee or back injury which might hinder exercise performance. Selected subjects were instructed to abstain from vitamin or nutrient supplements for five weeks prior to the start of the study. The study was approved by the Cornell University Committee on Human Subjects.

\section{Experimental Design}

The study was designed as two, three-periods by two 
treatment (exercise or no-exercise) crossover designs, in order to test the effects of two different levels of riboflavin in a simultaneously on-going study on the same subjects (Belko et al, 1985) (Table I). These six sequences were chosen to permit estimation and testing of both first and second order carryover effects due to exercise (Kershner and Federer, 1981). As both riboflavin intake groups had similar alterations in body weight, body composition and aerobic capacity with combined training-weight reduction, the two groups of subjects were combined for the purposes of the present analysis. The study design did mean, however, that different subjects were exercising or not exercising at different time points during the nine week duration of the study (Table I). This also meant that although all subjects underwent combined exercisetraining caloric restriction for at least three weeks, only four subjects (Nos. 1, 5, 7, 9) were exposed to a continuous six week period of exerise training while simultaneously reducing caloric intake.

TABLE I

Experimental deaign

\begin{tabular}{|c|c|c|c|c|}
\hline & \multirow{3}{*}{$\begin{array}{c}\text { Baseline } \\
2 \text { wks } \\
\text { Weight } \\
\text { Maintenance }\end{array}$} & \multicolumn{3}{|c|}{ Period } \\
\hline & & $\begin{array}{c}1 \\
3 \text { wks }\end{array}$ & $\begin{array}{c}2 \\
3 \text { wks }\end{array}$ & $\begin{array}{c}3 \\
3 \text { wks }\end{array}$ \\
\hline & & \multicolumn{3}{|c|}{$\begin{array}{l}\text { Restriction of } \\
\text { Energy Intake }\end{array}$} \\
\hline Group 1: & Subject & & & \\
\hline $1.16 \mathrm{mg}$ Riboflavin $4.2 \mathrm{MJ}^{-1}$ & 1 & $\mathbf{E}$ & $\mathbf{E}$ & $\mathbf{N}$ \\
\hline \multirow[t]{5}{*}{ (high intake) } & 2 & $\mathbf{E}$ & $\mathbf{N}$ & $\mathbf{N}$ \\
\hline & 3 & $\mathbf{E}$ & $\mathbf{N}$ & $\mathbf{E}$ \\
\hline & 4 & $\mathbf{N}$ & $\mathbf{N}$ & $\mathbf{E}$ \\
\hline & 5 & $\mathbf{N}$ & $E$ & $\mathbf{E}$ \\
\hline & 6 & $\mathbf{N}$ & $\mathbf{E}$ & $\mathbf{N}$ \\
\hline \multicolumn{5}{|l|}{ Group 2: } \\
\hline $0.94 \mathrm{mg}$ Riboflavin $4.2 \mathrm{MJ}^{-1}$ & 7 & $\mathbf{N}$ & $\mathbf{E}$ & $\mathbf{E}$ \\
\hline (moderate intake) & 8 & $\mathbf{E}$ & $\mathbf{N}$ & $\mathbf{E}$ \\
\hline & 9 & $\mathbf{E}$ & $\mathbf{E}$ & $\mathbf{N}$ \\
\hline & 10 & $\mathbf{N}$ & $\mathbf{N}$ & $\mathbf{E}$ \\
\hline & 11 & $\mathbf{E}$ & $\mathbf{N}$ & $\mathbf{N}$ \\
\hline & $12^{*}$ & $\mathbf{N}$ & $\mathbf{E}$ & $\mathbf{N}$ \\
\hline
\end{tabular}

$E=$ Exercise

$\mathrm{N}=$ Nonexercise

* = Excluded from final analysis

\section{Dietary Methodology}

Details of the dietary intake of the subjects have been previously described (Belko et al, 1985). Briefly, during the two week preliminary baseline period prior to the study proper, subjects consumed a weight-maintaining diet, individually adjusted in energy value. Subjects' daily energy intakes were subsequently cut back to a basic diet of $5.2 \mathrm{MJ}$ (1250 kcal) at the start of the study. The basic diet with nutrient supplements of $10 \mathrm{mg}$ iron as ferrous sulphate, $200 \mu \mathrm{g}$ folic acid, and $200 \mathrm{mg}$ calcium as calcium lactate, supplied the 1980 US recommended daily allowance (RDA) for women 18-40 years of age. Energy intake for Subject 11 was reduced to $7.1 \mathrm{MJ}(1700 \mathrm{kcal})$ rather than $5.2 \mathrm{MJ}$ (1250 kcal) due to her high energy need for weight maintenance (12.1 MJ or $2900 \mathrm{kcal}$ ).

\section{Training Protocol}

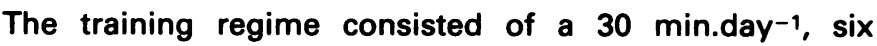

day.wk-1 supervised workout on a calibrated Tunturi cycle ergometer. Subjects pedalled at power outputs which elicited $75-85 \%$ of the maximum heart rate (HR max) during each exercise session. During each of the 3 three-week periods, resistance on the ergometer was gradually increased so that a greater proportion of each exercise session was spent at $85 \%$ of HR max. A training effect was evident throughout the exercise periods as higher resistance settings on the cycle ergometer were required to obtain a given heart rate.

\section{Body Composition and Maximum Oxygen Uptake}

Body composition and $\mathrm{VO}_{2}$ max were assessed at the end of the two-week baseline period and then at the end of each of the 3 three-week periods of exercise training and/or energy restriction. Practice tests were conducted during the baseline period to familiarise each subject with the test equipment.

Body composition was assessed by densitometry according to the method of Consolazio et al (1963) with direct correction of residual volume by the nitrogen washout technique (Wilmore, 1969). $\mathrm{VO}_{2}$ max was assessed by standard open-circuit spirometry techniques outlined in detail previously (Belko et al, 1985). In brief, the treadmill protocol involved walking continuously at $4.8 \mathrm{~km} \cdot \mathrm{h}^{-1}$ with a progressive $2.5 \%$ increase in treadmill trade every two minutes. Maximal aerobic capacity was defined as the highest measured oxygen uptake obtained during the test. A continuous exercise protocol was also utilised for the cycle $\mathrm{VO}_{2}$ max test (McArdle and Magel, 1970) with increments of $25 \mathrm{~W}$ every two minutes until the required pedalling cadence of $60 \mathrm{rpm}$ could no longer be maintained.

\section{Statistical Methods}

Values were reported as means \pm SEM. Repeated measures $t$ tests or analysis of variance (ANOVA) were employed as appropriate to determine the effects of three or six weeks of the training-calorie restriction combination on body weight, body composition, maximal oxygen uptake $\mathrm{WO}_{2}$ max I.min $\left.{ }^{-1}\right)$ and functional capacity $\left(\mathrm{VO}_{2} \max \mathrm{ml} \cdot \mathrm{kg}^{-1} \mathrm{~min}^{-1}\right)$. For the ANOVA tests, where the overall $F$ indicated significance, Newman-Keuls post hoc tests were performed to allow for all possible comparisons. In addition, differences between bicycle and treadmill values were assessed at the start of the study, and following three and six weeks of calorie restriction-exercise training combination. Subject 12 withdrew from the study before the end of the second three-week period as she was discouraged by her lack of weight loss. Thus her data were not included in the analysis.

\section{RESULTS}

Anthropometric data including height, weight, percentage of body fat.and lean body mass (LBM) are shown in Table II for all eleven subjects at the start of, and at 3 weekly intervals for the duration of the study. As can be seen from Table II, subjects progressively lost weight through the 9 week duration of the study. As estimated by densitometry, almost three quarters $(72 \%)$ of this weight loss was fat weight with loss of LBM making up the balance. This meant that the fat component calculated in $\mathrm{kg}$ decreased significantly at every time-point in the study. As a percentage of total body weight, this component also decreased throughout the study. In contrast, the decrease in 
TABLE II

Anthropometric characteriatics of moderately obese female subjects $(n=11)$

\begin{tabular}{lcccc}
\hline & Baseline & 3rd week & 6th week & 9th week \\
\hline Height (cm) & $164.1 \pm 2.1^{\circ}$ & & & \\
Body wt (kg) & $76.3 \pm 2.8^{\text {b }}$ & $73.6 \pm 2.7$ & $71.1 \pm 2.7$ & $68.8 \pm 2.5$ \\
Fat wt (kg) & $28.1 \pm 1.5$ & $26.7 \pm 1.5$ & $24.9 \pm 1.5$ & $22.7 \pm 1.5$ \\
$(\%)$ & $(37 \%)$ & $(36 \%)$ & $(35 \%)$ & $(33 \%)$ \\
LBM $(\mathrm{kg})$ & $48.2 \pm 1.9$ & $46.9 \pm 1.8$ & $46.2 \pm 1.8$ & $46.1 \pm 1.5$ \\
$(\%)$ & $(63 \%)$ & $(64 \%)$ & $(65 \%)$ & $(67 \%)$ \\
\hline
\end{tabular}

-Values are $M \pm$ SEM

bValues are significantly different from one another $(p<0.01)$ except where joined by a common underline

LBM (kg) was significant only during the first three weeks after which time LBM did not decrease and, as a percentage of total body weight, actually showed an increase.

Tables III and IV show the effects of the three and six weeks' energy restriction and exercise training on cycle ergometer and treadmill $\mathrm{VO}_{2}$ max respectively. Values are

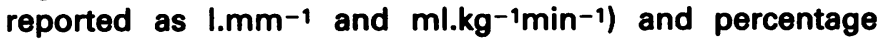
change $(\Delta \%)$ in an attempt to separate out the effects of exercise alone, from those of the combined tretments. Maximal oxygen uptake during cycling increased by $15 \%$ when expressed in 1. min-1 $^{-1}$ but by $20 \%$ when expressed in $\mathrm{ml}^{\mathrm{kg}} \mathrm{kgin}^{-1}$ (functional capacity). By six weeks, these improvements had increased to $23 \%\left(\mathrm{VO}_{2} \max I . \mathrm{min}^{-1}\right)$ and $31 \%\left(\mathrm{VO}_{2} \max \mathrm{ml} \mathrm{kg}^{-1} \mathrm{~min}^{-1}\right)$ respectively $(\mathrm{n}=4)$. Similar effects were observed on the treadmill (Table IV) although in the four subjects who trained for six weeks, no further increment in $\mathrm{VO}_{2} \max \left(1 . \mathrm{min}^{-1}\right)$ was seen, despite an additional increase in functional capacity due to further reductions in body weight. In comparing cycle to treadmill values, the group as a whole demonstrated a $10 \%$ lower cycle than treadmill $\mathrm{VO}_{2} \max$ both at the outset and following three weeks of cycle.training. In contast, the subpopulation ( $n=4$ ) of subjects who underwent the six weeks of combined exercise-training caloric restriction exhibited similar absolute values on the two ergometers before and after six weeks of bicycle training despite significant percentage increases on both bicycle and treadmill.

\section{DISCUSSION}

The effects of physical conditioning per se on body weight and body composition seem to be variable depending on the intensity and duration of the exercise programme and the initial body composition of the subjects. Franklin et al (1979) observed a slight $(3 \%, 2.55 \mathrm{~kg})$ but significant drop in body weight in obese females undergoing a 12-week combined calisthenics walk/jog programme although body weight in normal weight peers remained constant. Greater weight losses in obese exercising females were observed by Zuti and Golding (1976) who also included diet and dietexercise combination groups in their experimental design. However, in this study, the exercising group increased daily energy expenditure by $2.1 \mathrm{MJ}(500 \mathrm{kcal})$ which required approximately two hours of daily exercise carried out seven day. $\mathbf{w k}^{-1}$ for the 16 week duration of the study. Even greater exercise-induced weight loss in obese women was observed by Hadjiolova et al (1982). Although the training programme only lasted 6 weeks, subjects were physically

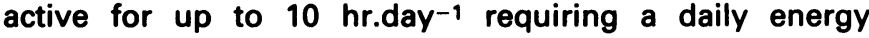
expenditure of 15.1-15.5 MJ (3600/3700 kcal). This resulted in an average $12 \mathrm{~kg}$ weight reduction over the time course of the study.

In contrast, Bjoïntorp et al (1973) and Krotkiewski et a (1979) were unable to show changes in body weight and composition or fat cell weight and number, of obese subjects of both sexes who exercised for 12 weeks. Similar findings were obtained by Mandroukas et al (1984) in severely obese females who underwent 12 weeks of training strenuous enough to produce a $20 \%$ increase in $\mathrm{VO}_{2} \max \left(1 . \mathrm{min}^{-1}\right)$.

TABLE III

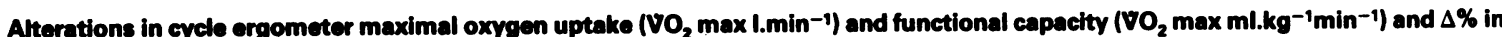
moderately obese females following three and six weeks combined energy-restriction and exercise training

\begin{tabular}{|c|c|c|c|c|c|c|c|}
\hline & & \multicolumn{2}{|c|}{ Before } & \multicolumn{2}{|c|}{ After } & \multirow{2}{*}{$\frac{\Delta \%}{\left(1 . \mathrm{min}^{-1}\right)}$} & \multirow{2}{*}{$\frac{\Delta \%}{(m)^{\left.-k g^{-1} \mathrm{~min}^{-1}\right)}}$} \\
\hline Time period & $n$ & I.min-1 & ml.kg-1 $\min ^{-1}$ & I. $\min ^{-1}$ & ml.kg-1 $\min ^{-1}$ & & \\
\hline 3 weeks' training & 11 & $2.0 \pm 0.1^{\circ}$ & $27.4 \pm 1.5$ & $2.3 \pm 0.1^{*}$ & $32.8 \pm 2.1^{* *}$ & $15 \%$ & $20 \%$ \\
\hline 6 weeks' training & 4 & $2.2 \pm 0.1$ & $30.8 \pm 2.8$ & $2.7 \pm 0.2^{*}$ & $40.3 \pm 2.0^{* *}$ & $23 \%$ & $31 \%$ \\
\hline
\end{tabular}

- Values are $M \pm S E M$

* $p<0.05$

$* * p<0.01$

TABLEN

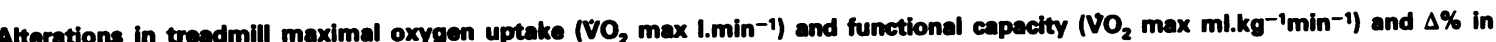
moderately obese fomales following three and six weeks combined energy-restriction and exercise training

\begin{tabular}{|c|c|c|c|c|c|c|c|}
\hline & & \multicolumn{2}{|c|}{ Before } & \multicolumn{2}{|c|}{ After } & \multirow{2}{*}{$\frac{\Delta \%}{\left(1 . \min ^{-1}\right)}$} & \multirow{2}{*}{$\frac{\Delta \%}{\left(\mathrm{ml}^{\mathrm{kg}} \mathrm{kg}^{-1} \mathrm{~min}^{-1}\right)}$} \\
\hline Time period & $n$ & I. min $^{-1}$ & ml.kg-1 $\min ^{-1}$ & I. $\min ^{-1}$ & $\mathbf{m l} \cdot \mathbf{k g}^{-1} \mathrm{~min}^{-1}$ & & \\
\hline 3 weeks' training & 11 & $2.3 \pm 0.1^{\circ}$ & $31.3 \pm 1.8$ & $2.6 \pm 0.1^{* *}$ & $37.0 \pm 3.1^{* *}$ & $13 \%$ & $18 \%$ \\
\hline 6 weeks' training & 4 & $2.3 \pm 0.2$ & $32.7 \pm 4.2$ & $2.6 \pm 0.2$ & $39.6 \pm 3.1 *$ & $13 \%$ & $21 \%$ \\
\hline
\end{tabular}

- Values are $M \pm S E M$

$* 0.05$

* $p<0.01$ 
The exercise regimen employed in these latter studies (Björntorp et al, 1973; Krotkiewski et al, 1979; Mandroukas et al, 1984) may explain the difference in findings. Although subjects exercised 55 min per session, three times a week, only a small fraction of this time was devoted to very intense exercise. The total surplus energy expenditure was therefore probably not very great. Forbes (1985) in his recent review on body composition as affected by physical activity and nutrition in both males and females summarises all the studies in which individuals trained for more than 60 hours. Of 17 groups examined, six lost at least $1 \mathrm{~kg}$ of weight, two gained at least $1 \mathrm{~kg}$, whereas the remaining nine varied less than $1 \mathrm{~kg}$ in either direction. This lead Forbes (1985) to conclude that exercise-training induced weight changes are normally very minimal.

In the present study therefore, it is unlikely that the weight loss of the subjects can be attributed to the exercise component of the study which only totalled either 9 hours $(3$ week group) or 18 hours ( 6 week group). The lack of any significant differences in average weight loss in the exercising versus non-exercising periods of the study $(2.7$ vs $2.6 \mathrm{~kg}$ and $2.4 \mathrm{vs} 2.6 \mathrm{~kg}$ ) for either the three or six week exercising group respectively would also support this hypothesis. Similar findings were observed by Warwick and Garrow (1981) in three obese females whose rate of weight loss following a reducing diet was not increased by 3-4 weeks of bicycle exercise. This was explained by the known training-induced increase in muscle glycogen stores and consequent uptake of additional muscle water.

Although the reduction in body weight seen in the present study was principally due to a reduction in fat weight, LBM was also reduced slightly. This finding disagrees with two previous studies which have looked at the combined effects of diet-restriction and exercise on body composition changes, in which LBM was maintained (Lewis et al, 1976; Zuti and Golding, 1976). However, in these two studies, the total exercise-induced energy expenditure was far greater than in the present study as the studies were of 17 and 16 weeks duration respectively. It thus appears that there may be a threshold of exercise intensity and/or duration for protecting lean body mass from diet-induced overall reduction of body weight. It is of interest that both Lewis et al (1976) and Zuti and Golding (1976) measured slight but non-significant increases in LBM, despite significant reduction in total body weight.

Despite the relatively short period of training in the current investigation, significant increase in maximum oxygen uptake and functional capacity were observed on both the treadmill and bicycle after only three weeks of bicycle exercise. As documented previously in the literature for average weight males (Hermansen and Saltin, 1969; Pechar et al, 1974), lower initial values for $\mathrm{VO}_{2}$ max were recorded on the bicycle than on the treadmill in this population of moderately obese females.

Three weeks of cycle training was apparently an insufficient period of time to elicit a specificity of training effect as cycle $\mathrm{VO}_{2}$ values were still lower than corresponding measurements on the treadmill. In the subpopulation of subjects that underwent six weeks of cycle training, no differences between cycle and treadmill $\mathrm{VO}_{2}$ max values were observed either at the outset or following six weeks of bicycle exercise. This prevented a comparison of our data with that of Pechar et al (1974) who saw significantly greater improvements in bicycle than treadmill $\mathrm{VO}_{2}$ max over the same period of time in male subjects who had lower initial cycle $\mathrm{VO}_{2}$ max values.

If the premise that the quantity of exercise performed had minimal effects on body weight is accepted, the dietinduced reduction in body weight certainly contributed to the increase in functional capacity measured as $\mathrm{VO}_{2}$ max ml.kg-1 $\mathrm{min}^{-1}$. Thus, this population of sedentary obese females was able to significantly increase its depressed $\mathrm{VO}_{2}$ max to the age-adjusted normal values (Drinkwater et al, 1975) with just three weeks of cycling. The reduction in body weight contributed approximately $20-25 \%$ of this improvement in functional capacity. In the four subjects (whose 3 week values were identical to those of the other subjects) who maintained the diet-training combination for a further three weeks, an additional increase in $\mathrm{VO}_{2}$ max I. $\min ^{-1}$ as well as functional capacity was observed on the cycle, but not on the treadmill. Again, further reductions in body weight contributed to the additional gains in functional capacity.

In summary, we have shown that in moderately obese females, energy restriction, when combined with 30 min.day ${ }^{-1}$ of cycling exercise carried out for three or six weeks duration, produces improvements in functional capacity ranging from 18-31 per cent, depending on mode of testing and duration of training. This increase is somewhat larger than normally seen in sedentary individuals and is due to the initially somewhat low functional capacities in these obese women and the fact that the bulk of weight lost due to energy restriction was fat weight.

\section{References}

Belko, A. Z., Meredith, M. P., Kalkwarf, H.J., Obarzanek, E., Weinberg, S. Roach, R., McKeon, G. and Roe, D. A., 1985 "Effects of exercise on riboflavin requirements: biological validation in weight reducing women". Am.J.Clin.Nutr. 41: 270-277.

Björntorp, P., de Younge, K., Krotkiewski, M., Sullivan, L., Sjöström, L. and Stenberg, J., 1973 "Physical training in human obesity III. Effects of long term physical training on body composition". Metabolism 22: 1467-1475.

Curtis, D. E. and Bradfield, R. B., 1971 "Long-term energy expenditure of obese housewives". Am.J.Clin.Nut. 24: 1410-1417.

Consolazio, C. F., Johnson, R. F. and Pecora, P., 1963. Physiological Measurements of Metabolic Functions in Man. New York: McGraw-Hill.

Drinkwater, B., Horvath, S. and Wells, C., 1975 “Aerobic power of females, ages 10 to $58^{\prime \prime}$. J.Gerontology 30: 385-394.

Forbes, G. B., 1985 "Body composition as affected by physical activity and nutrition". Federation Proc. 44: 343-347.

Franklin, B., Buskirk, E., Hodgson, J., Gahagan, H., Kollias, J. and Mendez, J. 1979 "Effects of physical conditioning on cardiorespiratory function, body composition and serum lipids in relatively normal-weight and obese middle-aged women". Int.J.Obesity 3: 97-109.

Hadjiolova, I., Mintcheva, L., Dunev, S., Daleva, M., Handjiev, S. and Balabanski, L., 1982 "Physical working capacity in obese women after an exercise programme for body weight reduction". Int.J. Obesity 6: 405-410.

Hermansen, L. and Saltin, B., 1969 "Oxygen uptake during maximal treadmill and bicycle exercise". J.Appl.Physiol. 26: 31-37.

Kershner, R. P. and Federer, W. T., 1981 "Two-treatment crossover designs for estimating a variety of effects". J.Am.Stat.Assoc. 76: 612-619.

Krotkiewski, M., Mandrewkas, K., Sjöström, L., Sullivan, L., Wetterqvist, H. and Björntorp, P., 1979 "Effects of long term physical training on body fat, metabolism and blood pressure in obesity". Metabolism 28: 650-658.

Lewis, S., Haskell, W. L., Wood, P. D., Manoogian, N., Bailey, J. E. and Pereira, M., 1976 "Effects of physical activity on weight reduction in obese middle-aged women". Am.J.Clin.Nutr. 29: 151-156.

McArdle, W. D. and Magel, J. R., 1970 "Physical work capacity and maximal oxygen uptake in treadmill and bicycle exercise". Med.Sci.Sports 2: 118-123.

Mandroukas, K., Krotkiewski, M., Hedberg, M., Woblewski, Z., Björntorp, P. and Grimby, G., 1984 "Physical training in women: Effects on muscle morphology, biochemistry and function". Eur.J.Appl.Physiol. 52: 355-361. 
Pechar, G. S., McArdle, W. D., Katch, F. I., Magel, J. R. and Deluca, J., 1974 "Specificity of cardiorespiratory adaptation to bicycle and treadmill training". J.Appl.Physiol. 36: 753-756.

Warwick, P. M. and Garrow, J S., 1981 "The effect of addition of exercise to a regime of dietary restriction on weight loss, nitrogen balance, resting metabolic rate and spontaneous physical activity in three obese women in a metabolic ward". Int.J.Obesity 5: 25-32.

Wilmore, J. H., 1969 "A simplified method for determination of residual lung volume". J.Appl.Physiol. 27: 96-106.
Woo, R., Garrow, J. S. and Xavier Pi-Sunyer, F., 1982a "Effects of exercise on spontaneous caloric intake in obesity". Am.J.Clin.Nutr. 36: 470-477.

Woo, R., Garrow, J. S. and Xavier Pi-Sunyer, F., 1982b "Voluntary food intake during prolonged exercise in obese women". Am.J.Clin.Nutr. 36: 478-484.

Zuti, W. B. and Golding, L. A., 1976 "Comparing diet and exercise as weight reduction tools". Physician Sports Med. 4: 49-53. 